Volume 6

2020

\title{
Introduction to the Special Issue on Applications of Judgment and Decision Making to Problems in Personnel Assessment
}

Edgar E. Kausel

Pontificia Universidad Catolica de Chile

Alexander T. Jackson

Middle Tennessee State University

Follow this and additional works at: https://scholarworks.bgsu.edu/pad

Part of the Human Resources Management Commons, Industrial and Organizational Psychology Commons, and the Other Psychology Commons

How does access to this work benefit you? Let us know!

\section{Recommended Citation}

Kausel, Edgar E. and Jackson, Alexander T. (2020) "Introduction to the Special Issue on Applications of Judgment and Decision Making to Problems in Personnel Assessment," Personnel Assessment and Decisions: Number 6 : Iss. 2 , Article 1.

DOI: https://doi.org/10.25035/pad.2020.02.001

Available at: https://scholarworks.bgsu.edu/pad/vol6/iss2/1

This Editorial is brought to you for free and open access by the Journals at ScholarWorks@BGSU. It has been accepted for inclusion in Personnel Assessment and Decisions by an authorized editor of ScholarWorks@BGSU. 


\title{
InTRODUCTION to the SPECIAL ISSUE ON Applications of Judgment and DeCISION Making to Problems in Personnel Assessment
}

\author{
Edgar E. Kausel ${ }^{1}$ and Alexander T. Jackson ${ }^{2}$ \\ 1. School of Management, Pontificia Universidad Católica de Chile \\ 2. Middle Tennessee State University
}

Personnel judgments and decisions are abundant in organizations. Some examples include deciding how to recruit as well as how many people should be recruited when staff planning, which candidates should be invited for an interview when hiring, or whose KSAs (knowledge, skills, and abilities) should be improved when training. Similarly, most performance appraisal systems rely on judgments (i.e., job performance ratings). As such, improving managerial judgment and choice is an important issue in industrialorganizational psychology research and practice. To better understand how people make choices and judgments in organizations, Scott Highhouse, the Journal Editor, asked us to curate studies for a special issue on the topic, adopting a judgment and decision making (JDM) perspective.

JDM research is an exciting field of study which encompasses researchers from diverse areas, from marketing to economics. Early decision research focused on optimal ways of making decisions for highly structured tasks (i.e., the normative approach; Edwards, 1961). More recent JDM research has allowed richer expressions of decision behavior and deeper insights into the psychological processes underlying choice (e.g., Fischhoff \& Broomell, 2020). This has opened the door for new research programs, which can be classified into two categories (Connolly \& Ordóñez, 2003). First, descriptive research examines biases that are common and consequential in decision making, such as overconfidence, confirmatory bias, and anchoring (Kahneman, 2011). Second, prescriptive research investigates ways to improve decision making competence or outcomes. An example of this is Thaler and Sunstein (2008)'s popular idea of nudging - an idea that contributed to Thaler receiving the Nobel Prize in Economics in 2017-which helps direct people in a particular way while making their decisions.

Given the breadth of how the JDM field can be applied to personnel contexts, we intentionally cast a wide net in our call for proposals. Specifically, we sought papers addressing issues such as using descriptive methods to identify how people make hiring decisions or performance judgments, identifying antecedents of decision-making skill, understanding and overcoming biases present in personnel contexts, and overcoming the barriers and resistance to evidence-based decision making, to name a few. Further, the call was open to laboratory studies, field studies, and conceptual/theoretical pieces. While this special issue does not tackle every issue, we believe the research presented here brings us closer to understanding JDM issues and being able to make specific prescriptions about JDM in personnel contexts. After the standard PAD double-blind peer review process, ${ }^{1}$ seven papers were accepted for this Special Issue. We organized these papers around three main themes, which we describe below.

Theme 1: Expert judgment in personnel decisions. Two of the papers included in this special issue are empirical studies that deal with the role of expert judgment in personnel decisions. This is an important area of research in industrial-organizational (I/O) psychology, especially given Highhouse's (2008) seminal paper on the problems of intuition in personnel selection in general and what he termed the myth of expertise in particular. In the first paper, Yu and Kuncel (2020) seek to replicate a classical study - but one

Edgar E. Kausel

School of Management, Pontificia Universidad Católica de Chile Av.Vicuña Mackenna 4860, Macul, Santiago, Chile.

Email: ekausel@uc.cl

Alexander T. Jackson

Middle Tennessee State University

MTSU Box 87, Murfreesboro, TN 37132

Email: Alexander.jackson@mtsu.edu 
that may surprise many personnel selection practitionersin JDM and the psychology of prediction. Dawes and Corrigan (1974; see also Dawes, 1979) found that, given a set of predictors, linear models using random weights (!) of these predictors outperformed expert judgment in GPA prediction and psychiatric diagnosis. Yu and Kuncel examine whether what they call mindless consistency may also occur in hiring decisions.

In the second paper, Voss and Lake (2020) examine expertise in the context of an important topic in recent years: nontraditional metrics. Research has suggested that traditional validity measures such as $r$ and $R^{2}$ are often poorly understood for most audiences (e.g., Brooks et al., 2014). As such, researchers have considered nontraditional metrics as a way to enhance understanding. Voss and Lake examine whether these metrics have an effect in increasing understanding of validity information and whether this leads to heightened perceived usefulness of structured over unstructured interviews. They also study whether the magnitude of this effect is different for experts (people with hiring experience) vs. non-experts. Results from these studies on expertise may surprise some readers.

Theme 2: Strategies to improve personnel decisions (and how they may backfire). The second set of papers deal with the prescriptive standpoint of JDM: How to improve personnel decisions. This is important given the scientist-practitioner gap and how people tend to assign weight to suboptimal selection methods such as the unstructured interview over more structured ones (Kausel et al., 2016). The first paper under this theme, by Thiele et al. (2020), examines ways to increase decision aid use among decision makers. Decision aids, such as statistical tools and algorithms, may give important information in improving predictions by consistently integrating information (see also $\mathrm{Yu}$ \& Kuncel, 2020); however, people tend to give them less weight than they should (Dietvorst et al., 2015). Thiele and colleagues argue that one way practitioners may be nudged into using decision aids is by giving them feedback about the (generally poor) accuracy of their predictions. This had been suggested as a debiasing method (e.g., Slaughter \& Kausel, 2013); however, Thiele and colleagues are the first to empirically test it. They use an interesting experiment to do so.

The second paper seeking to improve personnel decisions is by Kuncel and Dahlke (2020). The authors examine how, in decision sets of 3 or 4 options, a seemingly irrelevant choice may influence employee hiring decisions. Specifically, they examine the decoy effect (also known as the asymmetric dominance effect). This is by no means novel in the personnel selection literature (see Highhouse, 1996;

1 We appreciate the contribution of conscientious and thoughtful reviewers that helped us put this special issue together!
Slaughter et al., 2011). However, what is novel about this paper is how this effect, often understood as an irrational choice, can actually counter other biases (such as racial or gender bias) that may be present in a personnel selection system and potentially improve diversity hiring. This is a good example of how decision makers may be nudged into making better employee decisions. We believe that this paper can trigger interesting ideas for practitioners.

The third paper under this theme is by Nolan et al. (2020). Nolan et al. (2016), based on Meehl's (1986) ideas, had put forward an interesting theory that may explain why hiring managers and consultants underweight decision aids. The authors argued that professional decision makers fear that the use of decision aids and standardized procedures may reduce the perceived value of their contributions and expert judgment (i.e., threat of technological unemployment [TOTU]). In the paper included in our special issue, Nolan et al. aim to further develop the theory of TOTU in hiring decisions by using a different methodology than previously used. In addition, and perhaps more importantly, Nolan and colleagues expand their theory by examining potentially negative effects of techniques commonly used to promote personnel decision aids and standardized hiring practices. Stated differently, they study whether seemingly benign practices to improve the validity of a personnel selection system may backfire due to employee resistance of being replaced by standardized procedures or mechanical decision making.

Theme 3: Theoretical and conceptual papers. In addition to the two empirical themes, two papers clearly clustered together to form a theoretical/conceptual theme. First, Dalal et al. (2020) argue that the volume of information that personnel decision makers have access to when selecting between candidates is ever increasing. While the traditional adage claims that "knowledge is power," Dalal et al. make an argument that not all knowledge is powerful. They specifically caution decision makers against using nondiagnostic information (i.e., information that is irrelevant to the decision at hand). Because individuals responsible for making hiring decision often obtain information from multiple sources, including applicants' social media pages, nondiagnostic information abounds. Dalal et al. present a framework for understanding the different types of nondiagnostic information, explain why it can impact decision making, and present strategies for reducing the effect such irrelevant information can have on the hiring decision.

In the second paper, Blacksmith et al. (2020) provide a theoretical framework uniting the areas of individual differences, decision-making aptitude, and decision performance. The authors argue that decision making should be considered as a key dimension of job performance and present ways for identifying the critical decision-making behaviors. As part of the framework, the authors also present a review 
of proximal and distal individual differences predicting decision-making behavior, such as cognitive ability, domain knowledge, and affect. Additionally, the framework Blacksmith et al. presents includes specific methodological recommendations for assessing the decision-making predictor and criterion space. While a lot of the information in their review is not new, one of the key contributions of their framework is presenting all of the information from previously disconnected areas in one place.

Where do we go from here? The papers included in this special issue begin to tackle important questions and issues regarding JDM within the context of personnel assessment and decisions. These researchers investigated biases, ways to improve decision making in selection, decision makers' fears of being replaced by technology, ways to overcome biases, ways to improve reliance on decision-making tools, the effect of different weighting schemes compared to expert judgments in selection, how advancing technologies in interviews impacts decision-makers' intention to use the technologies, and ways to better communicate validity information of selection tools. Additionally, recommendations for how to appropriately use information and for incorporating JDM into performance are offered. However, we still have much to learn.

Based on the papers within this issue, there are some obvious next steps for researchers. First, a common idea across several of the papers is the issue of trust in decision-making tools. It seems that before we can get people to use these tools we must find ways to improve the trust people have in the tools. Therefore, we call on researchers to specifically study the variables that influence trust as well as specific interventions that can be used to improve trust in these tools. Second, while there is a wealth of research examining the role of biases in decision making, there is a need to further understand biases and the ways to overcome or even circumvent the impact of biases in personnel decisions. For instance, the Black Lives Matter movement has brought media attention to the biases in hiring, training, and evaluating law enforcement personnel. Last, the two papers that present a theoretical/conceptual argument open the door for researchers to evaluate their claims.

Beyond the scope of these papers, there are many issues that have yet to be fully examined. For instance, indecisiveness has to date been relatively unexplored. Many questions can be raised about indecisiveness, such as are people more likely to rely on decision-making tools if they are indecisive? Do indecisive people fall prey to the same JDM biases? Additionally, what remains to be identified are specific ways people can be trained to improve their decision-making skill or competence, especially in the context of personnel assessments and decisions. Last, and perhaps most importantly, we call on researchers to replicate the research within this special issue as well as classic and seminal JDM findings within applied personnel assessment contexts. The replicability crisis within psychology demands our attention and efforts to reproduce the findings of previous work.

In conclusion, we hope these papers pique the interests of our readers and inspire new directions for research (as well as previous directions in the case of replications). We hope researchers continue uniting the often separated fields of JDM and personnel psychology. We anticipate that as this multidisciplinary research continues, great advances in hiring and assessment practices can be made.

\section{REFERENCES}

Blacksmith, N., McCusker, M. E., \& Hayes, T. L. (2020). A unifying framework to study workplace decision-making aptitude and performance. Personnel Assessment and Decisions, 6(2), 65-74.

Brooks, M. E., Dalal, D. K., \& Nolan, K. P. (2014). Are common language effect sizes easier to understand than traditional effect sizes? Journal of Applied Psychology, 99, 332-340.

Connolly, T., \& Ordóñez, L. (2003). Judgment and decision making. In W. C. Borman, D. R. Ilgen, \& R. J. Klimoski (Eds.), Handbook of psychology: Industrial and organizational psychology (Vol. 12) (pp. 493-517). John Wiley \& Sons.

Dalal, D. K., Sassaman, L., \& Zhu, X. S. (2020). The impact of nondiagnostic information on selection decision making: A cautionary note and mitigation strategies. Personnel Assessment and Decisions, 6(2), 54-64.

Dawes, R. M. (1979). The robust beauty of improper linear models in decision making. American Psychologist, 34, 571-582.

Dawes, R. M., \& Corrigan, B. (1974). Linear models in decision making. Psychological Bulletin, 81, 95-106.

Dietvorst, B. J., Simmons, J. P. \& Massey, C. (2015). Algorithm aversion: People erroneously avoid algorithms after seeing them err. Journal of Experimental Psychology General, 144, 114-121.

Edwards, W. (1961). Behavioral decision theory. Annual Review of Psychology, 12, 473-98.

Fischhoff, B., \& Broomell, S. B. (2020). Judgment and decision making. Annual Review of Psychology, 71, 331-355.

Highhouse S. (1996). Context-dependent selection: The effects of decoy and phantom job candidates. Organizational Behavior and Human Decision Processes, 65, 68-76.

Highhouse, S. (2008). Stubborn reliance on intuition and subjectivity in employee selection. Industrial and Organizational Psychology: Perspectives on Science and Practice, 1, 333342.

Kahneman, D. (2011). Thinking, fast and slow. New York, NY: Farrar, Straus and Giroux.

Kausel, E. E., Culbertson, S. S., \& Madrid, H. P. (2016). Overconfidence in personnel selection: When and why unstructured interview information can hurt hiring decisions. Organizational Behavior and Human Decision Processes, 137, 27-44.

Kuncel, N. R., \& Dahlke, J.A. (2020). Decoy effects improve diversity hiring. Personnel Assessment and Decisions, 6(2), 31-37.

Meehl, P. E. (1986). Causes and effects of my disturbing little book. Journal of Personality Assessment, 50, 370-375. 
Nolan, K. P., Carter, N. T., \& Dalal, D. K. (2016). Threat of technological unemployment: Are hiring managers discounted for using standardized employee selection practices? Personnel Assessment and Decisions, 2, 30-47.

Nolan, K. P., Dalal, D. K., \& Carter, N. T. (2020). Threat of technological unemployment, use intentions, and the promotion of unstructured interviews in personnel selection. Personnel Assessment and Decisions, 6(2), 38-53.

Slaughter, J. E., \& Kausel, E. E. (2013). Employee selection decisions. In S. Highhouse, R. S. Dalal, \& E. Salas (Eds.), Judgment and decision making at work, SIOP organizational frontiers series (pp. 57-79). New York, NY.

Slaughter, J. E., Kausel, E. E., \& Quiñones, M. A. (2011). The decoy effect as a covert influence tactic. Journal of Behavioral Decision Making, 24, 249-266

Thaler, R. H., \& Sunstein, C. (2008). Nudge - improving decisions about health, wealth and happiness. London: Penguin Books.

Thiele, A., Jackson, A. T., Stremic, S. M., \& Howes, S. S. (2020). Does feedback increase decision aid use among hiring professionals?. Personnel Assessment and Decisions, 6(2), 2030.

Voss, N. M., \& Lake, C. J. (2020). Communicating validity information to differentially experienced audiences: The effects of numeracy and nontraditional metrics. Personnel Assessment and Decisions, 6(2), 11-19.

Yu, M. C., \& Kuncel, N. R. (2020). Pushing the limits for judgmental consistency: Comparing random weighting schemes with expert judgments. Personnel Assessment and Decisions, 6(2), 1-10. 